\title{
CARDIAC MYXOMA
}

\section{A CLINICAL AND PATHOLOGICAL STUDY}

BY

\author{
R. E. M. FAWCETT AND E. MILFORD WARD
}

From the City General Hospital, Leicester

Received April 12, 1939

We wish to place on record this case of so-called cardiac myxoma because it appears that only rarely do descriptions of this interesting lesion appear in British publications. We have found only one British reference during the last nine years, the case of Gilchrist and Miller (1936) which will be discussed later in this paper; on the other hand, numerous references have appeared during the last few years in America and Germany. The lesion is a rare one, much less common than the appearance of secondary neoplasm. The latter were found by Welch (1931) in 0.22 per cent. of autopsies, and Ward (1934) reports a corresponding figure of 0.3 per cent., whereas Lymburner (1934) states that primary neoplasms of the heart were found in 0.05 per cent. of autopsies, of this number 75 per cent. were innocent and the majority of innocent tumours were myxomas.

\section{DESCRIPTION OF THE CASE}

A woman aged 60 was admitted for the first time to the City General Hospital, Leicester, on March 4, 1938, with the diagnosis of diabetes mellitus and bronchitis. She had previously complained of rheumatic pains in the shoulders and since 1925 she had had various attacks of epigastric pain and vomiting. More recently it had been known that her blood pressure was above the normal. During her stay in hospital her diabetic condition was readily stabilized, nothing abnormal was discovered in her cardiovascular system except slight hypertension, B. P. 170/90 mm., and she was discharged after fifteen days.

Almost immediately after returning home she began to suffer from fainting attacks, but on no occasion was she seen by her medical attendant whilst in an attack. Præcordial pain also occurred and was associated with marked dyspnœa and some cough. Præcordial pain and dyspnœa now continued until December 1938, when diarrhœa started. This symptom became so pronounced that the patient was readmitted to hospital on January 14, 1939, for investi- 
gation. No abdominal lesion could be found to account for this symptom and no abnormal physical signs were found in the heart other than slight left ventricular hypertrophy. Her diabetes had remained controlled and she appeared to be in satisfactory health until January 18, when for the first time in hospital there was a complaint of faintness and dizziness which was considered to be a mild attack of hypoglycæmia. A similar attack occurred five days later, and this responded immediately to a hypodermic injection of adrenalin. On the evening of January 28 she had a very severe attack without any previous warning, and when seen she was pulseless and was thought by the sister of the ward to be dead. An injection of 15 minims of adrenalin was given into the left ventricle and 3 c.c. of coramine were injected intravenously. Within two minutes the pulse could be felt at the wrist and the patient recovered consciousness and began to talk.

On auscultation of the heart it was found to be fibrillating and it continued to fibrillate for about 3 minutes before normal rhythm was resumed. The patient appeared quite comfortable for an hour, then, again, without warning, she collapsed ; 15 minims of adrenalin were given into the heart and again the patient, who had for a second time been pulseless, recovered, became a good pink colour and was able to talk. She remained in a satisfactory condition and appeared to go to sleep naturally. About three-quarters of an hour later she slept normally for forty minutes, and then she died suddenly in her sleep. The provisional diagnosis was coronary thrombosis.

\section{POST-MORTEM Findings (ABSTRACT ONLY)}

Diagnosis : Acute heart failure, tumour of the left auricle, hyperpiesis.

There was no excess of pericardial fluid. Some hypertrophy of the left ventricle was present with well marked atheroma of the aorta ; but the coronary vessels were excellent and the probe passed readily along them without finding any obstruction. No alteration in the size of any of the valve apertures was found, and all the valve cusps were thin and showed no evidence of previous infection.

When palpating the mitral valve a fairly firm tumour could be felt almost filling the left auricle. On approaching the left auricle from behind, this tumour could be more readily seen (Fig. 1). It was attached to the interauricular septum by a pedicle $23 \mathrm{~mm}$. long and $16 \mathrm{~mm}$. broad, the lower point of this pedicle being attached $8 \mathrm{~mm}$. above the attachment of the mitral cusps. The tumour itself was roughly spherical, with a diameter of $40 \mathrm{~mm}$. The length of the pedicle allowed the tumour to be pushed into the orifice of the mitral valve (Fig. 2) and also to fall over the openings of the pulmonary veins. In appearance the tumour was shiny, and there were many small polypi on the surface. It was white in colour save where hæmorrhage beneath the surface was shining through. It was peculiar in consistency, being somewhat rubbery or elastic. On section the tumour was yellow in colour and homogeneous, with several areas of recent hæmorrhage. There was no evidence of scarring 


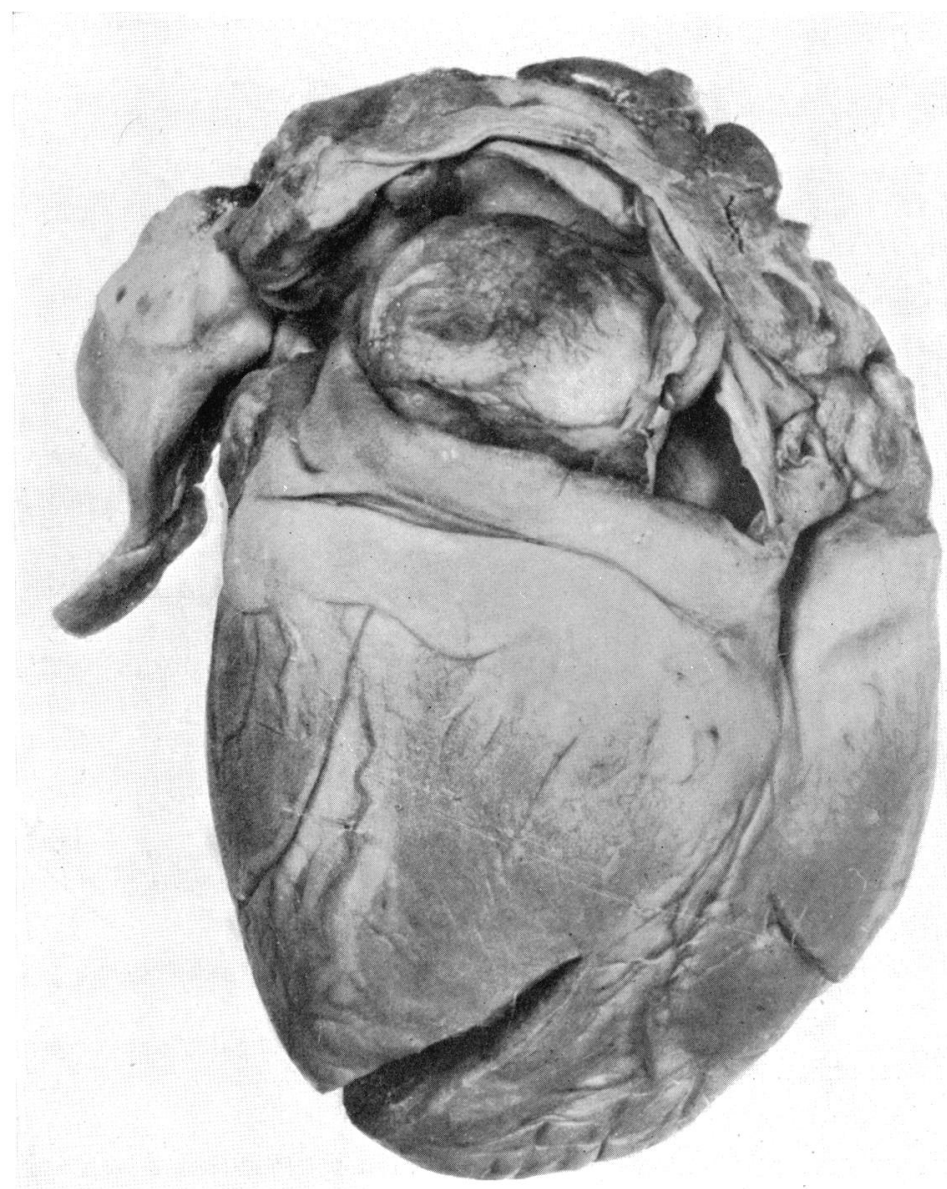

Fig. 1.-Posterior aspect of heart showing myxoma lying in the left auricle ; it is attached to the interauricular septum by a pedicle.

or contracture. (There was considerable shrinking on preservation, and this shows in the plate.)

The lungs showed congestion throughout, this being somewhat more marked at the bases, and there was considerable emphysema. The liver was slightly enlarged and was also congested. The kidneys were smaller than normal, with a very rough granular surface. On section there was increase of pelvic fat and decrease in the size of the cortical layer. The intercortical vessels stood out prominently.

Histological sections were prepared from the base of the tumour and from its free surface. These were stained by hæmatoxylin and eosin, by Van Gieson's stain, by mucicarmine, and by thionin. The tumour appeared lined by a single layer of endothelial cells under which was a thin layer of fibrous tissue. Immediately beneath this layer were masses of inflammatory cells and new 


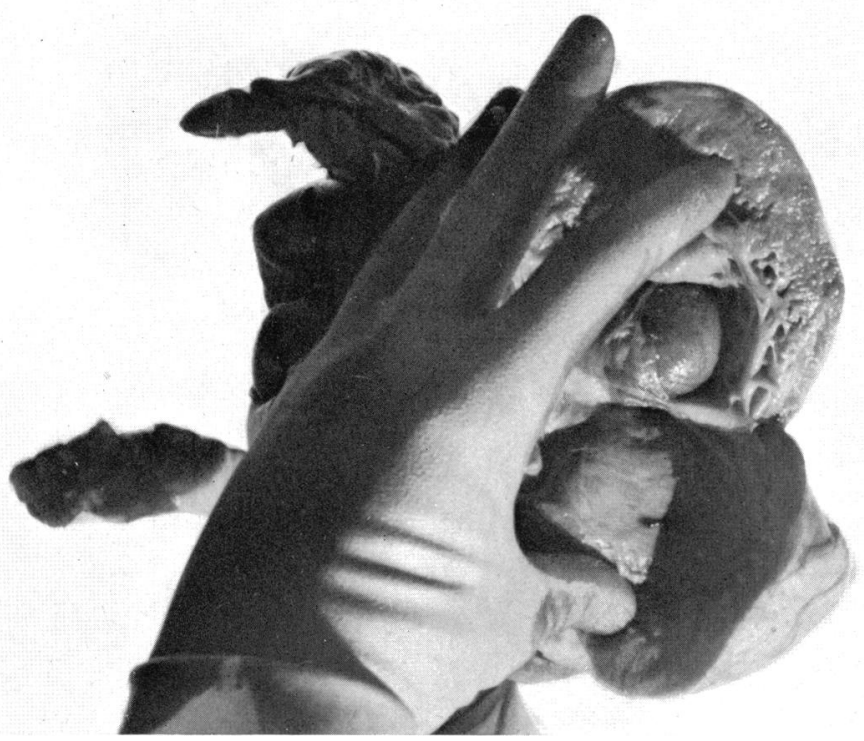

FIG. 2.-Photograph of heart before fixation, showing smooth and shiny tumour projecting through mitral orifice.

blood vessels or groups of endothelial cells which represented new capillaries awaiting canaliculization. Large masses of blood pigment were present, probably hæmosiderin, but little intercellular pigment could be found. Deeper within the section the tumour proper was found. This consisted of a finely fibrillar matrix, cells being relatively scanty. The matrix stained faintly blue with hæmatoxylin, but fairly deeply with mucicarmine and thionin. The cells were large with a vesicular nucleus, and in many cases they showed bipolar or unipolar projections.

Within the tumour proper groups of endothelial cells and capillaries with a single cell lining were found and blood pigment masses were still present, but were less marked. The myxoma cells tended to be arranged around these new blood vessels. The large areas of hæmorrhage were mainly confined to the subendocardial region, but deeply within the tumour there were small groups of free red cells. A small amount of elastic tissue was found throughout the sections examined. The picture was therefore one of a myxoma, the number of new blood vessels present hardly justifying the term angiomyxoma. 


\section{Clinical Features}

.No one has yet reported the successful diagnosis of a primary innocent cardiac neoplasm during life. Pavlowsky (1919) made a diagnosis of primary sarcoma of the left auricle, but at the autopsy it was discovered that the tumour was on the right side. A primary malignant tumour, an invasive tumour of a sarcomatous type, was diagnosed by Shelburne (1935) in a case of a male aged 24 with a large blood-stained pericardial effusion.

In many of the reported cases, however, the diagnosis was suggested by

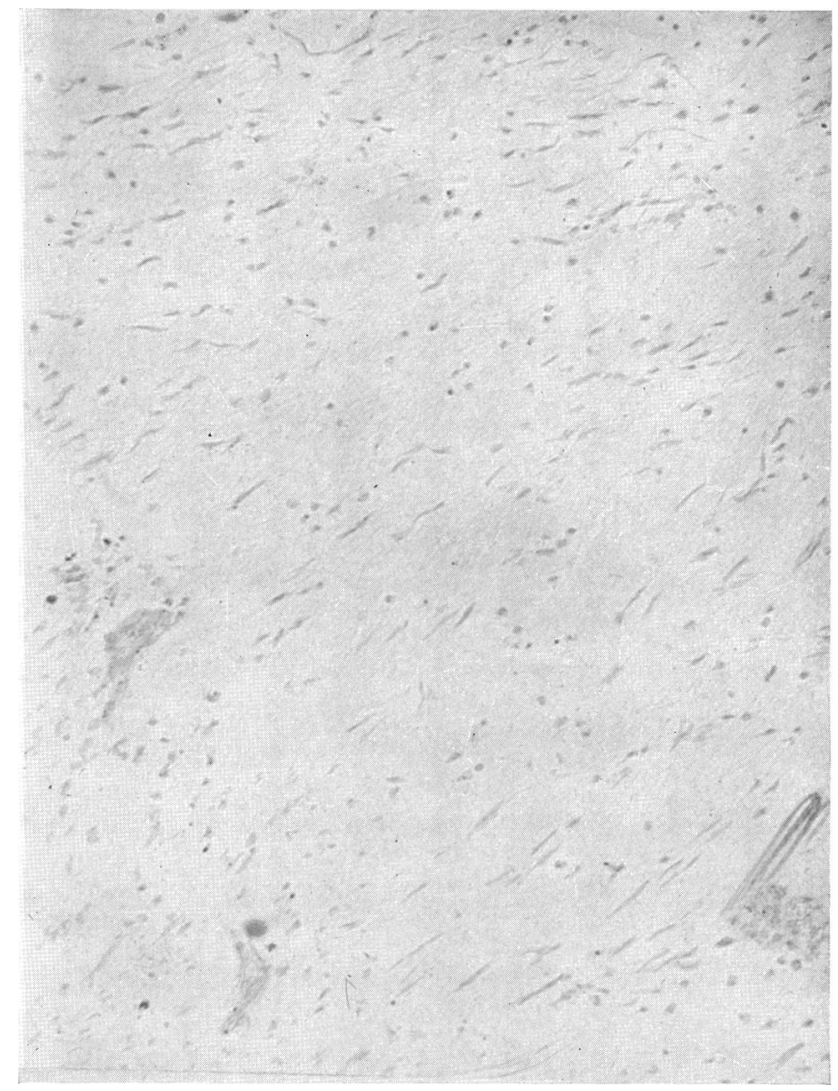

FIG. 3.-Section of cardiac myxoma $(\times 100)$, showing fibrillar matrix and elongated cells.

certain points in the history, the physical signs, or in the reaction of the patient to treatment, and so it may be of interest to consider a few of the clinical pictures which have been described as follows.

(1) Mitral Stenosis with Congestive Heart Failure.

The picture of mitral stenosis with congestive heart failure is the commonest one to be described. A typical case is described by Jensen (1934) in a woman aged 32 who had complained of shortness of breath and œdema for two months, 
and clinically showed ascites and a heart condition typical of mitral stenosis. There are three important points which appear, however.

(a) The cardiac signs and especially the murmur vary from time to time. Thus in the case described by Bien and Ch'in (1936) a rough highpitched systolic murmur present all over the præcordium, but loudest at the apex, was heard when the patient was in hospital but whilst an out-patient a rumbling mid-diastolic murmur or a third heart

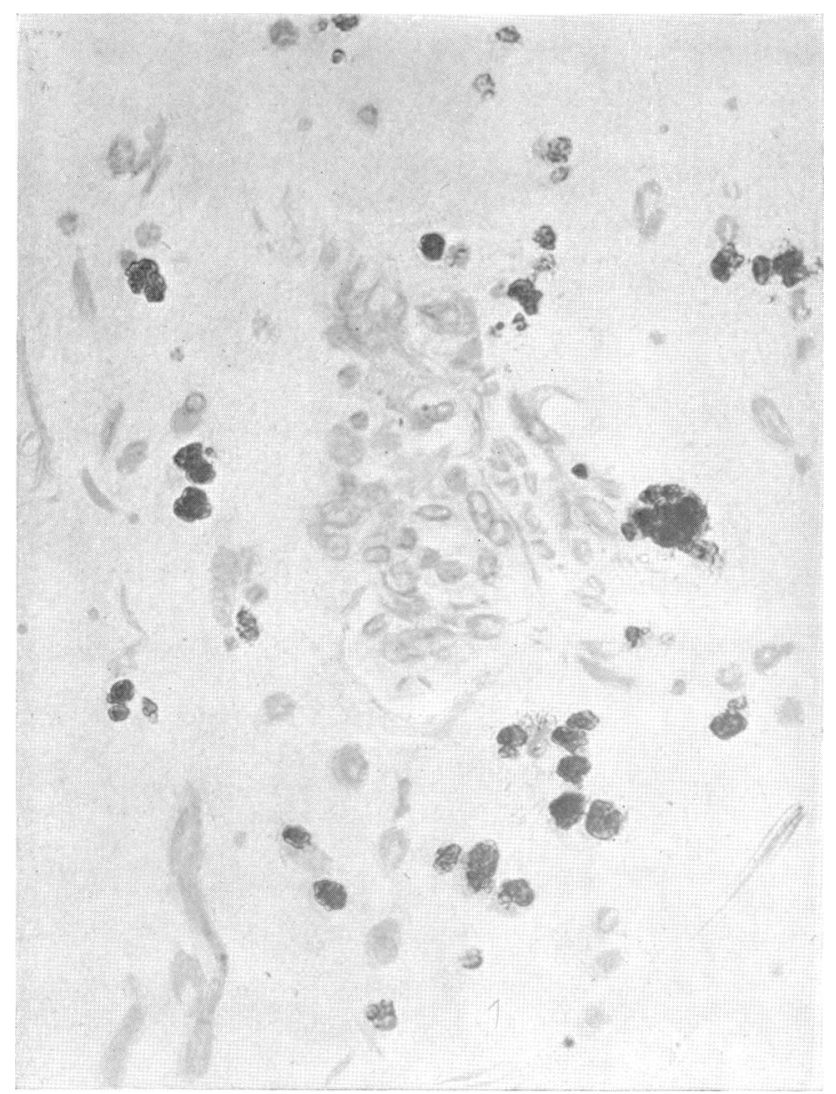

FIG. 4.-Section of cardiac myxoma $(\times 450)$, showing cells arranged near blood vessels ; large amount of pigment.

sound prolonged into a diastolic murmur was found at the apex. Gilchrist and Miller point out that the obstruction of an auriculoventricular orifice by a tumour retards the blood flow and narrows the stream and this fictitiously produces the ausculatory signs of a valvular stenosis.

It is obvious that in certain positions the tumour will fall away from the valve orifice, with the result that the blood flow is not impeded and the heart sounds change in character. 
(b) These patients rarely give a previous history of antecedent diseases, such as rheumatic fever, chorea, growing pains or recurrent sore throats, which might have lead up to a mitral stenosis.

(c) The history of cardiac debility is usually a short one.

(2) Fainting Attacks and Loss of Consciousness with the Patient Erect

The case described by Houck and Bennett (1929-1930) demonstrates well this group of cases. The patient was a female, aged 44 , who had always enjoyed the best of health and denied all previous history of rheumatism. She was an athletic type and indulged in a considerable amount of swimming. Suddenly, six weeks before admission to hospital, she had a fainting attack as she stood up after leaving the water. After this, fainting attacks recurred at weekly intervals, always whilst the patient was erect. There followed in rapid succession dyspnœa with œdema of the ankles, cyanosis and orthopnœa. On admission to hospital, presystolic and systolic murmurs at the apex and a moderate degree of enlargement of the heart were found. She died suddenly in her sleep during the first night in hospital. At the autopsy a tumour was found in the left auricle which fitted snugly into the mitral orifice. It seems clear that in this group of cases the symptoms depend upon the tumour completely blocking the mitral orifice for a very short time whilst the patient is erect. They depend upon the tumour having a sufficiently long pedicle to allow some movement.

Another case of this kind is described by Gorlitzer (1934). Here a woman was admitted to hospital unconscious with twitching in all the extremities and with preserved reflexes. She had had several previous attacks of an " hysterical " type. At autopsy a myxoma of the left auricle was found with emboli in the left anterior cerebral artery, both middle cerebral arteries and the left posterior cerebral artery.

\section{(3) Sudden and Unexpected Death}

This group of cases really consists of the final stages of the ones previously described, although there is often no previous history of illness leading up to the final attack. Here the tumour probably does not fall back from the mitral orifice and death ensues. Lymburner's case (1934) was admitted to hospital for the treatment of septicæmia which was the result of a self-induced abortion, and she died suddenly. There were no abnormal clinical features found in the heart. In Houck and Bennett's case previously described and also in our case death took place quietly during sleep.

\section{(4) Relentless Progress of Heart Failure in spite of Adequate Rest and Digitilization}

We have already mentioned the case described by Bien and Ch'in, since it demonstrated the point of varying heart murmurs with the position of the 
patient, and it is also an excellent example of this type of case. The patient was a male aged 59 when first admitted to hospital in 1934 complaining of shortness of breath which had been present for three weeks. During a stay in hospital of one month he made some improvement and was discharged on a maintenance dose of $0.1 \mathrm{~g}$. of digitalis daily and was instructed to rest at home. This he did. During the following year the cardiac reserve became slowly reduced, so that from being able to walk two-thirds of a mile he could now walk less than a hundred steps, and in January 1935 signs of congestion were found and the patient was re-admitted to hospital. Thus although resting and receiving adequate digitalis and although he had been seen frequently at the cardiological clinic, the lesion first noted in January 1934 slowly progressed during the year until death took place in February 1935. This progress of symptoms is probably dependent upon the slow growth of the tumour ; with more rapid onset or with more rapid retrogression of health dependent upon rapid increase in size such as would follow hæmorrhage into its substance.

\section{(5) Abnormal Radiological Shadows.}

The enlargement of the left auricle caused by the presence of a large tumour will sometimes produce alterations in the radiological contour of the heart. Bennett and Konigsberg (1938) describe a case, admitted to hospital with a pelvic abscess, who died whilst under an anæsthetic for its treatment. A skiagram showed a large bulge in the region of the pulmonary conus which was considered to be due to congenital abnormality. There was a myxoma in the left auricle. The tumour described by Gilchrist and Miller produced a projection into the posterior mediastinum together with marked enlargement of the heart both to the right and to the left.

\section{(6) Cardiac Irregularities}

Cardiac myxomas rarely produce irregularities of the pulse. This is readily understood, because as innocent tumours they do not interfere with the conducting mechanism. It is comparatively rare for even extensive involvement of the myocardium with secondary deposits from carcinoma or sarcoma to produce obvious changes in the electrocardiogram. Paroxysmal auricular tachycardia is described by Gilchrist and Miller in a male aged 57 who had complained of præcordial pain for two and a half months. These attacks of pain were brought on by lying flat in bed and were relieved by sitting up. At the height of an attack he "fell away in a trance." Each attack lasted from 10 to 15 minutes. The first diagnosis considered was an anxiety neurosis, but the presence of slight cyanosis and dyspnœa suggested an organic cause for the symptoms. The electrocardiogram showed short runs of auricular paroxysmal tachycardia and numerous auricular extrasystoles intermingling with normal rhythm. These attacks of paroxysmal tachycardia were reduced in 
frequency under digitalis therapy, although whilst in hospital right-sided heart failure developed which did not respond to treatment.

\section{(7) Paroxysmal Dyspnoea}

If the tumour interferes with the orifices of the pulmonary veins instead of with the mitral orifice it will cause sudden back pressure in the pulmonary circulation and thus give rise to pulmonary œdema and dyspnœa. It has frequently been noted that in cases of heart failure due to the presence of a tumour in the left auricle the breathlessness is out of all proportion to the degree of decompensation. Bien and Ch'in say that their patient was suddenly awakened at midnight with a sense of suffocation and had profuse perspiration and palpitations only relieved by expectorating large quantities of frothy sputum. Gilchrist and Miller also describe attacks of paroxysmal nocturnal dyspnœa. Ernstene and Lawrence (1936) report a case, not of myxoma but of an occluding thrombus in the left auricle, in which for several months there had been paroxysms of breathlessness which caused the patient to sit up in bed, when he promptly lost consciousness. Each attack lasted for less than fifteen minutes.

After considering the groups of cases described above, we would suggest that no particular symptom or sign can be taken as diagnostic of an intracavitary tumour of the heart, save perhaps the rare abnormal skiagram; but that, if in any patient the history, the physical signs, and the subjective symptoms do not readily fall together into a complete picture, then the presence of such a tumour should be considered. The case can then be reassessed with this diagnosis in view. Especially might this be true in cases of mitral stenosis who strongly deny all antecedent illness and in whom the cardiac disability is an exceedingly short one.

\section{Pathology}

Although at least 100 descriptions of cardiac myxomas have been published the majority of reported cases are not accepted by all pathologists. Writing in 1922 Husten said that, of the 71 reported cases he discussed, only 9 were true myxomas, all the others being thrombi. On the other hand Ribbert (1924) disagrees with this view and considers that the majority at least of the reported cases are true tumours. Bacaloglu et al. (1933), call these tumours "thrombus myxoides" and say that "les myxomes du cœur sont a l'envers de la conception classique des tumeurs des plus rares," and Clerc et al. (1937) say that between the true myxomatous or myxosarcomatous tumours and organized thrombi all intermediate forms are possible.

The possible origin of these tumours may be listed :

(1) They are true myxomatous tumours arising, as Ribbert suggests, from myxomatous rests in the region of the fossa ovalis in the interauricular septum.

(2) They are thrombi undergoing myxomatous degeneration. 
(3) They are œdematous thrombi, the matrix not being true myxomatous tissue but fibrin swollen by œdema fluid.

(4) They represent myxomatous degeneration in a fibroma.

The main argument lies, it seems to us, between the first two of these possible origins. Are these true tumours or are they thrombi undergoing myxomatous degeneration? The present view seems to be that they are true tumours. Thus Yater (1931) says : "It seems to me that the argument concerning the nature of these myxomatous masses is all in favour of their neoplastic origin," and Ewing (1928) says "Whilst many of the larger tumours may be difficult to identify it seems unlikely that a simple organizing blood clot can reproduce the positive features of the true myxomas. Hence the great majority of the reported cases of cardiac myxoma are probably genuine."

The presence of small myxomas on the heart valves is not disputed, and cases have been reported by Jaleski (1934) and by Abrahamer (1931), but the origin of the large masses found in the auricle more often on the left than on the right is a debated question. The arguments in favour of these masses being true neoplasms are

(1) Myxomas are always found in the auricles, whereas thrombi are more common in the ventricles. They arise near the fossa ovalis where it is known that myxomatous rests may occur.

(2) There is no previous history in the majority of cases which would lead to stasis in the heart chambers and so allow thrombi to form. Samuel Wilks (1889) very beautifully describes the formation of antemortem thrombi or " polypi" in the dilated chambers of the heart due to the stagnation of blood in the recesses of the columnæ, especially in the left ventricle and the right auricle. He stresses that there must be stagnation to allow thrombus formation.

(3) Myxomas are uniform throughout except where there is hæmorrhage ; there is no evidence of the lamination found in the more common antemortem thrombus.

(4) Microscopically, myxoma shows a poverty of cells, but those present are characteristically spindle or star shaped cells with processes anastomosing or disappearing into the matrix. They may be scattered throughout the tumour or be arranged round the blood vessels or underneath the capsule if the tumour shows peripheral growth. The characteristic cells will not, of course, be found in a thrombus. Elastic tissue may be found in either case. The blood vessels of a tumour are arranged in a uniform manner throughout the neoplasm, and in a thrombus they tend to be scanty deep within the mass.

(5) A thrombus tends to retract and will show scarring, whilst a neoplasm may be smooth, villous, papillomatous or polypoid.

(6) Chemically the presence of mucin cannot be used as an argument either way, since mucin may be found in an undoubted thrombus. The blood pigment in a myxoma is hæmosiderin throughout, whereas in a thrombus the peripheral 
pigment is hæmosiderin and the pigment at the centre is the iron-free hæmatoidin.

It is unlikely that these neoplasms are fibromas undergoing myxomatous degeneration because :

(1) They are the commonest primary tumour of the heart, whereas Yater says that only 25 cases of fibroma had been reported up to 1931 . The fibromas are never larger than a cherry and in the majority of cases they were placed on the heart valves.

(2) Myxomatous degeneration in an innocent tumour is usually looked upon as a prelude to malignant change and myxosarcomas are exceedingly rare. If all myxomas were an intermediate stage between an innocent neoplasm and a malignant one we should expect obvious primary malignant tumours of the heart to be more frequent than they appear to be in the literature.

Our case answers as far as possible the criteria laid down for the diagnosis of a cardiac myxoma. The tumour was totally unlike any thrombus we have ever seen in a heart, and we believe it to be a true neoplasm.

\section{SUMMARY}

(1) The clinical features and postmortem findings in a case of cardiac myxoma are described.

(2) The symptoms and signs in reported cases of cardiac myxoma are reviewed. Obstruction of the mitral orifice by the tumour may produce murmurs like those of mitral stenosis, or may cause fainting attacks related to posture or sudden and unexpected death. Obstruction of the pulmonary veins may cause paroxysmal dyspnœa.

(3) The pathology of cardiac myxoma is discussed and the various views as to their origin are mentioned. Reasons are given for regarding them as true myxomatous tumours rather than as thrombi or fibromas which have degenerated.

We wish to thank Dr. E. C. Hadley, Medical Superintendent of the City General Hospital, Leicester, for his permission to publish this case and the Librarians of the Royal Society of Medicine and the British Medical Association for much help with the bibliography.

\section{REFERENCES}

Abrahamer, I. (1931). Zbl. Gynäk., 55, 2,344.

Bacaloglu, C., Iliescu, C., and Raileanu, C. (1933). Presse méd., 41, 2074.

Bennett, D. W., Konigsberg, J., and Dublin, W. (1938). Amer. Heart J., 16, 117.

Bien, C. W. and Ch'in, K. Y. (1936). Chin. med. J., Supp. 1, 64.

Clerc, A., Gauthier-Villars, P., Delamare, J., and Rogé (1937). Arch. Mal. Coeur, 30, 361.

Ernstene, A. C. and Lawrence, J. C. (1936). Amer. Heart J., 12, 618.

Ewing, J. (1928). Neoplastic Diseases, 3rd ed., Philadelphia and London.

Gilchrist, A. R. and Miller, W. G. (1936) Edin. med. J., 43, 243.

Gorlitzer, V. (1934). Zbl. allg. Path. path. Anat., 61, 115.

Göttel, L. (1919). Dtsch. med. Wschr., 45, 937.

Houck, G. H., and Bennett, G. A. (1929-30). Amer. Heart J., 5, 787.

Husten, K. (1922). Beitr. path. Anat., 71, 132. 
Jaleski, T. C. (1934). Amer. J. Path., 10, 399.

Jensen, C. R. (1934). Northwest Med., 33, 394.

Lymburner, R. M. (1934). Canad. med. Ass. J., 30, 368.

Ribbert, H. (1924). Handbuch der Speziellen Pathologie, Anatomie und Histologie, Berlin. Vol. 2, 276.

Shelburne, S. A. (1935-6). Ann. intern. Med., 9, 340.

Ward, E. M. (1934). Lancet, 2, 250.

Welch, R. A. (1931). Med. Bull. Veterans Administration, 7, 772.

Wells, H. G. (1920). Chemical Pathology, 4th ed. Philadelphia and London.

Wilks, S. (1889). Lectures on Pathological Anatomy, 3rd ed., London.

Yater, W. M. (1931). Arch. Intern. Med., 48, 627. 